Western University

Scholarship@Western

2019

Parental Licensing and Discrimination

Carolyn McLeod

Western University, cmcleod2@uwo.ca

Andrew Botterell

Western University, abottere@uwo.ca

Follow this and additional works at: https://ir.lib.uwo.ca/philosophypub

Part of the Philosophy Commons

Citation of this paper:

Andrew Botterell and Carolyn McLeod, "Parental Licensing and Discrimination" in G. Calder, J. De Wispelaere, and A. Gheaus, eds., Routledge Handbook on the Philosophy of Childhood and Children (Routledge, 2018). DOI: 10.4324/9781351055987 


\section{Parental Licensing and Discrimination}

C. McLeod and A. Botterell

\section{Introduction}

In order to protect children from risks associated with bad parenting, some philosophers have recommended that all parents be licensed, in much the same way in which drivers of motor vehicles and many professionals, such as physicians, are licensed (see, e.g., LaFollette 1980, 2010). In this chapter, we clarify what parental licensing is, describe philosophical theories about it, and assess these theories in terms of how well they deal with problems of discrimination in parental licensing.

Our discussion revolves around the following fact: that while some parentsnamely adoptive and foster parents-are licensed, people who become parents through (unassisted or assisted) reproduction generally are not. This situation represents, in general terms, the status quo on parental licensing in most Western jurisdictions. Our argument in this chapter proceeds against this backdrop, although it should be noted that most philosophers do not approach the problem of parental licensing in this way. To the contrary, they begin by asking whether there should be parental licensing at all, thereby ignoring or downplaying the fact that parental licensing already occurs in the context of adoption and foster parenting. This is a problem with most philosophical theories about parental licensing.

A further problem with these theories is that they tend to pay insufficient attention to forms of discrimination that may be inherent in, or result from, a system of parental licensing. For example, by situating these theories in relation to the status quo, we aim to show how many of them reinforce what philosophers have called "biologism" or "bionormativity": the privileging of families formed through biological reproduction over families formed in other ways (Haslanger 2009; Baylis and McLeod 2014). While much of our discussion focuses on biologism, we also touch on other forms of discrimination that parental licensing can cause or exacerbate, such as classism, sexism, homophobia, racism, and ableism. Our view is that any adequate proposal in favour of parental licensing must take worries about discrimination seriously. Unfortunately, most philosophical proposals fail to do so.

The chapter proceeds as follows. In Section II we explain what parental licensing is before describing, in Section III, the current status quo on parental licensing. Then, in Section IV, we turn to philosophical arguments for and against different parental licensing schemes. Our main goal throughout is, again, to highlight ways in which these schemes could be discriminatory or could promote discrimination that targets adoptive and foster families in particular. 


\section{The Nature of Parental Licensing}

Parental licensing involves restrictions on the freedom to parent a child that are imposed by the state on individuals who may never have mistreated children. In requiring that individuals be licensed, the state demands that they show some competency in being a parent before they actually become one in a social sense. Since typically, the relevant restrictions are prospective in nature-they occur before someone has had the opportunity to parent a child-what lies at the core of parental licensing is "prior restraint"; people are restrained in the activity of parenting prior to showing any incompetence in doing so (i.e., by harming a child; LaFollette 1980: 188).

Any process of licensing is meant to test whether someone is competent to perform an activity at some appropriately specified level, both now as well as in the future. The standards of competence could be set very high, thereby excluding a relatively large number of applicants, namely those who are predicted not to perform the activity very well. Alternatively, the standards could be set quite low, thereby excluding only a small number of applicants, namely those who are predicted to perform the activity poorly. As Hugh LaFollette explains (1981), licensing therefore involves a standard of behavior together with a prediction about future performance. Since its purpose is to "decrease potential [future] harm," it must focus on whether someone will meet the required standard of performance, not simply whether they do so now. (LaFollette 1981: 181. For disagreement, see Frisch 1981.) The purpose of parental licensing is therefore to determine whether someone will treat their children well or, more weakly, will not mistreat them.

What is interesting about parental licensing, however-and what differentiates it from many other types of licensing -is that predictions about future competence are typically not based on assessments of present performance. ${ }^{1}$ Instead, these predictions are based on two assessments: first, on whether, by possessing certain capabilities, such as emotional or financial capabilities, individuals are likely to exhibit competence in parenting at the desired level in the future; and second, on whether a given individual indeed possesses these capabilities. By contrast, with many other forms of licensing, applicants must actually perform the relevant activity at the desired level before they are granted a license. For example, one has to drive a car competently for an assessor before the state will issue one a driver's license, or one must have given competent patient care during a medical residency before being licensed to practice a particular form of medicine. The fact that parental licensing typically involves only an assessment of capabilities deemed to be relevant to the performance of the licensed activity (namely parenting) may not make this form of licensing unique compared to all other forms. All the same, this aspect is important and helps to explain some of our misgivings about certain schemes of parental licensing proposed by philosophers.

\footnotetext{
${ }^{1}$ LaFollette makes a similar point (1981: 182), explaining that the "grounds for the prediction" with parental licensing differ from other forms of licensing, such as the licensing of drivers.
} 


\section{The Status Quo on Parental Licensing}

As we have noted, many philosophers have ignored or downplayed the fact that parental licensing actually occurs. In many jurisdictions, some individuals-namely, adoptive and foster parents - must be licensed before they are legally allowed to parent a child. Although these people do not receive an actual license to parent, similar to a driver's license, what they undergo is still properly called parental licensing. They are prevented from becoming a parent unless they complete a home study, which itself involves criminal background checks together with assessments of one's financial situation, physical and mental health, place of residence (i.e., whether it is child friendly), and family history including relationships with one's parents and any current or previous spouse(s). ${ }^{2}$ Additional requirements may include follow-up visits from social workers and, less commonly, attendance at government-mandated parenting classes.

To be sure, the state sometimes interferes with the ability of other parents to care for children, although not in a way that involves licensing. Rather, child welfare investigations occur when there are serious concerns that parents of any kind are abusing or neglecting their children. Here, the state intervenes to determine whether there is abuse or neglect, not whether there will be such harm. ${ }^{3}$ It is therefore not licensing parents through these interventions. In general, non-adoptive and non-foster parents do not require a license to parent.

To be sure, the status quo on parental licensing is somewhat more complex than what we have just described. This is because not all adoptive parents have to fulfill licensing requirements such as a home study. Indeed, it is common for people who do "family-member" or "relative" adoptions, such as stepparent adoptions, not to be subject to such screening (see McLeod \& Botterell 2014: 154). The status quo therefore requires licensing mainly for non-family member adoptions. It also usually involves no licensing for people who become parents via assisted or unassisted reproduction, although in some cases of assisted reproduction, a subsequent adoption-one that may involve licensing - is required for the same-sex partner of a woman who gives birth to a child who is biologically related to her, but not her partner. Also, there are jurisdictions (e.g., the U.K.) where licensing must occur before certain forms of assisted reproduction

\footnotetext{
${ }^{2}$ See McLeod \& Botterell (2015) and Vopat (2007) for descriptions of what home studies are like, specifically in Canada.

${ }^{3}$ Such investigations are reactive when it comes to child abuse and neglect (or heightened concern about it), while parental licensing is proactive (Vopat 2007: 73). Moreover, they may result not in the removal of the children from the parents' care, but rather in supervision of the family by social workers.
} 
can proceed, namely with contract pregnancies (i.e., surrogacy) and/or pregnancies conceived through the use of donor embryos. ${ }^{4}$

Although the status quo is descriptive of a certain social and institutional reality-some prospective parents are licensed and others are not-it also has important normative implications. The reason is that this system privileges biological connections to the child who will be parented. If one is the biological parent of a child, or the spouse of someone who is the biological parent of a child (unless one is a samesex spouse and lives in a jurisdiction where same-sex spouses do not count as family members for the purposes of adoption), then one will be spared the intrusion of a home study, the need to attend parenting classes, and so on. One will be able to become a parent without having to show that one is competent to do so.

\section{Philosophical Positions on Licensing and Discrimination}

While most philosophers do not focus their discussion of parental licensing on the status quo, many acknowledge that some parents are already licensed and question whether this situation is morally consistent or fair. According to some, the absence of licensing for biological parents is problematic because it exposes large numbers of children to significant risks of serious harm (e.g., LaFollette 1980, 2010; Vopat 2007; Overall 2015). These philosophers believe that the status quo is insufficiently general, and that there should be greater licensing of parents than what presently occurs. Others are opposed to greater licensing, either because they think the status quo is justified, or because they question the appropriateness of licensing parents in the first place (e.g., Archard 1990, 2004; Engster 2010; De Wispelaere \& Weinstock 2012). Still others argue-without specifying whether there should be more or less licensing of parents - that we need a new status quo, since the current one is simply unjustified. (McLeod \& Botterell 2014; Botterell \& McLeod 2015, 2016). This section summarizes these different positions and discusses whether, in defending them, philosophers deal appropriately with the problem of discrimination in parental licensing.

\section{(A) Arguments in favour of greater licensing}

In his classic paper, "Licensing Parents," Hugh LaFollette argues that all parents should be licensed (1980). His motivation is child-centric: licensing parents is required in order to prevent child abuse or neglect. Some philosophers have followed LaFollette in recommending universal parental licensing (though not always for child-centric reasons; see, for example, Taylor 2009). ${ }^{5}$ By contrast, others have suggested that parental licensing should expand, yet only into the realm of assisted reproduction. Our discussion

\footnotetext{
${ }^{4}$ In the U.K., licensing is required for the intended parents of children created through contract pregnancy and embryo donation (see http://www.hfea.gov.uk/1424.htm|\#5).

${ }^{5}$ Taylor favours universal licensing as a means of restricting parenthood to people who can parent without public support.
} 
of arguments in favour of greater licensing than what now occurs with the status quo will center mainly on LaFollette's pioneering work, including his later paper, "Licensing Parents Revisited" (2010). Yet along the way, we will also mention arguments made by other philosophers.

LaFollette (1980) makes the following case for universal parental licensing. We are justified in licensing individuals who engage in an activity $A$ if (i) A can harm others, (ii) the "safe performance" of A requires a certain competence, and (iii) we have a "moderately reliable procedure" for determining the presence or absence of such competence in relation to A (1980: 183). ${ }^{6}$ This argument applies to activities such as driving a car and engaging in many professions - for example, medicine, law, or being an airline pilot - that now require individuals to be licensed before pursuing the activity. But interestingly, according to LaFollette, the argument also applies to parents, because parenting meets conditions (i)-(iii).

To see why parenting satisfies the above criteria, consider the following. Parenting, when done badly, can cause serious physical and psychological harm to children (LaFollette 1980: 184-5; 2010: 331-2). What is more, to avoid such outcomes, parents need to have certain dispositions, a certain amount of knowledge (i.e., about children, and perhaps about themselves), and certain abilities (e.g., to feed, care for, and nurture children) (LaFollette 2010: 332-3). They need, in other words, to be competent at parenting. LaFollette believes that moderately reliable procedures exist to test for this competency (see Mangel 1988; for criticism see Sandmire and Wald 1990)although he claims that if that is not the case, then we could "undoubtedly" develop such tests in the future (1980: 192). The benefits of parental licensing also outweigh its costs, according to LaFollette, particularly if it aims - as he thinks it should - at eliminating very bad parenting, rather than marginally bad or simply not very good parenting.

LaFollette's main argument in favour of parental licensing is therefore not concerned with the unfairness of licensing only some parents, although he does recognize that some, and only some, parents are now licensed. (He mentions only adoptive parents in this context.) Rather, his concern is with the interests of children. He explains in this context that adoptive parents are much less likely than biological parents to abuse or neglect their children, a fact that he and others attribute to the licensing of these parents (1981: 183; see also Vopat 2007). He also sets the standard of parental competency that he wants all parents to meet lower than the standard currently expected of adoptive (and foster) parents. In light of these points-along with the fact that "none of us would seriously entertain abandoning" adoption licensing-LaFollette

\footnotetext{
${ }^{6}$ In "Licensing Parents Revisited," LaFollette adds the criterion that the benefits of licensing should outweigh its costs (LaFollette 2010: 328, 336). This point significantly amends his 1980 position and raises the question of which "costs" should be considered in this balancing act. For discussion, see De Wispelaere and Weinstock (2012).
} 
concludes that we are "rationally compelled" to accept his proposal for greater parental licensing (1981: 183).

Still, LaFollette recognizes that many people will have serious objections to universal parental licensing. He considers a number of objections, including, among others, the claim that people "have a right to have children" (by which he means a right to have biological children), that the potential for the "unintentional misuse" or "intentional abuse" of tests of parental competency by administrators is too great, and that a universal licensing scheme would be too difficult to enforce. Concerning the right to have children, LaFollette states that it is not unconditional, but rather exists only insofar as "one is not going to abuse or neglect" one's children (1980: 188; for a similar argument in support of a conditional right to parent, see Brighouse and Swift 2006). He also dismisses concerns about the misuse and abuse of competence tests by saying that "there is no reason to believe that the licensing of parents is more likely to be abused [or misused] than driver's license tests or other regulatory procedures" (1980: 192). (He is less dismissive about these concerns, however, in his 2010 paper.) Lastly, concerning enforceability, LaFollette insists that we could deal with "violators" - that is, people who have children without first obtaining a parental license-in a fair and reasonable way. For example, we "might not punish parents at all-we might just remove the children and put them up for adoption" (as if there was no punishment in that (!); 1980: 193).

In a significant departure from his 1980 paper, LaFollette argues in his 2010 paper that we should not punish people at all for failing to obtain a parental license before having children, but rather should reward people for doing so, with tax breaks for example. He calls this scheme one of "limited licensing." Although limited licensing is not without its problems-LaFollette worries that it "favours the rich," who do not need tax breaks, and may hurt the poor, who, if they are unlicensed, will pay more money in taxes and have less money to care for their children relative to others - he again believes that the benefits outweigh the costs (339). Other philosophers would disagree, however, in particular Mark Vopat, who argues against a proposal that is very much like LaFollette's later one (namely, Westman's 1994 proposal). Such voluntary licensing would, according to Vopat, "result in discrimination against those of lower economic classes," and is objectionable for this reason (2007: 82).

Like LaFollette, Vopat argues in favour of greater licensing than what exists with the status quo. He defends a form of universal licensing that he calls "minimal licensing," and that is designed specifically to minimize the ways in which parental licensing can be discriminatory (2007: 83-6). He, more than most philosophers, is concerned with the problem of discrimination in parental licensing, although as we shall see, Vopat's licensing scheme does not reduce the discriminatory effects of parental licensing as much as we believe it could or should.

Yet another philosopher who has argued in favour of greater parental licensing is Christine Overall (2015). Unlike LaFollette and Vopat, however, Overall contends, not 
that all parents should be subject to (or, in the case of the later LaFollette, rewarded for) licensing, but rather that a greater subset of parents than just adoptive and foster parents should be licensed. For her, this subset is composed of individuals who become parents via contract pregnancy. She believes that it is appropriate to require parental licensing whenever there is a transfer of responsibility for the care of a child from one person (or institution, if the child is a ward of the state) to another. In her view, such transfers are what justify parental licensing in the case of adoption and foster care, yet they occur as well in contract pregnancies: responsibility for the care of a child is transferred from the contract pregnant woman to the commissioning individual or couple. Thus, according to Overall, the reason for requiring licensing for adoptive and foster parents exists as well in the case of contract pregnancies and speaks in favour of licensing the individuals who commission these pregnancies.

To summarize this discussion, some philosophers have argued that current parental licensing should be expanded to include all parents or just some parents who engage in assisted reproduction. As well, the later LaFollette believes that any expansion of licensing should be voluntary, so that only parents who want to be rewarded (e.g., with tax breaks) will be licensed. Let us reflect on how well these philosophers handle the concern that parental licensing can be discriminatory, before moving on to describe the views of those who disagree with greater licensing. And let us start with discrimination against non-biological families. On the assumption that the status quo on parental licensing reinforces biologism, the philosophers who argue for greater licensing oppose this outcome to some extent, though not overtly. For example, both LaFollette and Vopat think that there are no reasons why biological parents should not be licensed, if adoptive or foster parents are licensed. Also, in arguing that current licensing should be expanded to include the intended parents in contract pregnancies, including parents who may be genetically related to the resulting child(ren), Overall rejects - again not overtly, and also clearly not to the same degree as LaFollette and Vopat-the privileging of biological relations within the status quo.

Still, none of these philosophers completely rejects the status quo and the biologism that may underlie it. For notice that the views of the early LaFollette and of Vopat are consistent with there being more intrusive licensing for adoptive and foster parents than for biological parents. The early LaFollette argues for a scheme of licensing for biological parents that, by his own admission, would be less onerous than the sort of licensing that occurs in adoptions. Vopat's minimalist licensing scheme is similar in this regard. Whether adoptive (and foster) parents would be subject to the less rigorous licensing they propose for biological parents is left unclear in their papers, although given how valuable they believe the licensing of adoptive parents is in preventing child abuse and neglect, it is doubtful that they would want to change it.

Another issue has to do with whether the administrators of parental licensing schemes will rely, either explicitly or implicitly, on their own prejudices in deciding who gets a license. Recall that the early LaFollette responds to this problem by saying that 
"there is no reason to believe" that the "intentional abuse" or "unintentional misuse" of licensing would occur more frequently with parental licensing than with forms of licensing that we already accept $(1980,192)$. Yet we doubt that is actually true. Three considerations are relevant here. First, consider how many stereotypical images of minority groups target, directly or indirectly, their ability to be a good or decent parent (and how relatively few stereotypical images concern their ability to be a decent driver, for instance). Examples include images of Black women as matriarchs or welfare moms (Hill Collins 2000), of gay men as pedophiles, of indigenous people as lazy or violent, and of people with disabilities as helpless and vulnerable. ${ }^{7}$

Second, with parental licensing, there is arguably more opportunity for discriminatory biases to enter into assessments of people's competence. Recall that with such licensing, there is usually no test of present performance. Evaluators do not get to see whether the person can parent at the desired level, but rather have to make a judgment based on whether this person possesses capabilities that are thought to be relevant to good or decent parenting. Discriminatory biases can enter in at various stages: deciding which capabilities are relevant to parenting, at what level the applicant needs to possess them, and whether the applicant does indeed possess them at this level.

The result is that discriminatory bias is more of a worry with parental licensing than it is with many other forms of licensing. Although the testing with other types of licenses can certainly be biased, we suspect that there is less chance of bias with them than with parental licensing. Consider as well that the effects of such bias -in particular, when licenses are denied to those who are discriminated against-can be much more damaging in the case of parental licensing, compared to other licensing. That is true based on the value of opportunity lost (parenting vs. driving, for example) and what the denial of the license expresses about the individual (that she would be a bad parent vs. a bad driver).

As this all-too-brief discussion reveals, the concern about discriminatory bias in parental licensing is somewhat complex, but should be central to debates about parental licensing. Yet most philosophers pay little attention to this issue. Vopat and Overall mention the problem, but do not go into depth about it (although to her credit, Overall recognizes that such concerns are significant and that "to explore them thoroughly would require another paper": 360). Moreover, while Vopat is particularly concerned about discrimination in parental licensing, his minimalist scheme demands that licensed parents have a high school diploma (2007: 84), a requirement that does not exist with licensing for adoption or foster care, and which arguably discriminates against people who have little formal education. To be fair, Vopat insists on this

\footnotetext{
${ }^{7}$ To be clear, in our view, these stereotypes are as likely to corrupt current licensing schemes as they are to corrupt the schemes that LaFollette proposes. We are concerned here simply with how well LaFollette deals with concerns about discrimination with any sort of parental licensing.
} 
criterion only because, when conjoined with a mandatory high school parenting class, it would "allow us to assume a certain minimal level of parental knowledge" (2007: 85). But if that is the justification for the requirement of a diploma, then why not simply require stand-alone parenting classes instead, as some governments do now for adoption and foster care?

\section{(B) Arguments against greater licensing}

Unlike the philosophers we have just discussed, others oppose the imposition of greater licensing on parents, and object in particular to universal parental licensing (with most of their work targeting LaFollette's 1980 paper). Although these philosophers do not set out to defend the status quo, they are generally content with it-with the exception of Jurgen De Wispelaere and Daniel Weinstock, who believe the status quo should be reevaluated from the ground up (2012; more on their view below). Moreover, those who are satisfied with the status quo (i.e., on parental licensing) are not necessarily satisfied with the status quo on the extent to which the state monitors or supports parents. On the contrary, most of these philosophers contend that the state ought to invest more in parenting through greater monitoring of, or social assistance for, parents.

Among the reasons philosophers have given for objecting to LaFollette's (1980) proposal, and proposals like it, are that licensing will not effectively weed out people who would be very bad parents; that, overall, greater monitoring of parents by the state is a better solution to the problems of child abuse and neglect than licensing parents; and that the problems of enforcing licensing schemes are too great. Let us comment briefly on each of these objections.

First, some-such as Lawrence Frisch (1981) and David Archard (1990, 2004)argue that it would be a mistake to license more parents because parental licensing would not in fact succeed in reducing child abuse and neglect. The reason is that it could not reliably predict which individuals will mistreat their children. For example, Frisch suspects that most child abuse and neglect occurs in response to extraordinary social or economic stress, and that since licensing cannot duplicate these conditions and test how people react under them, it cannot prevent child abuse and neglect (1981: 176). By contrast, Archard claims that child abuse is the result in part of individual psychopathology, but that research on child abuse has so far failed to "produce a clear and distinct psychological picture of the abusing parent" (2004: 188). Hence, we cannot predict with sufficient accuracy which people will abuse their children and should therefore be denied a parental license.

Second, various authors have suggested that over time, licensed parents would have to be re-evaluated to ensure that they are still fit to care for their children. But if that is the case, then wouldn't it be simpler, as these philosophers ask, simply to monitor parents' treatment of their children in a more comprehensive way than we do now? Archard insists that such a solution would be less "cumbersome" than a system of 
repeat licensing (1990: 191). It also would not involve many of the difficulties of licensing, including the need to make predictions about people's future performance in parenting, predictions that would have to "cover all eventualities" (Archard 1990: 191).

Third, there is the question of whether parental licensing could be enforced in a fair or reasonable way. This problem-variously described in terms of the "viability" (Engster 2010) or "feasibility" (McLeod \& Botterell 2014) of licensing - receives its best treatment from Daniel Engster (2010). Engster explains that it would be difficult to enforce parental licensing without causing women great hardship, and thus without furthering gender inequality. For example, women without a license to parent a child who experience an unplanned pregnancy would be forced to consider having an abortion or having a child with whom they were in a close physical relationship for nine months taken away from them (Engster 2010: 247-248). To be sure, they could try to hide their pregnancy, which would involve foregoing assistance from health care professionals during pregnancy and birth; but, of course, this option would pose serious risks to their health and the health of their child (2010: 247-248). Men, on the other hand, would not generally face choices as distressing as these as a result of parental licensing. Even after the birth of their child, their situation would not be the same as that of women who give birth. For instance, given the unequal economic status between women and men, the choice between staying with a partner who is denied a parental license and keeping one's child would not be as difficult, on average, for heterosexual men compared to heterosexual women (2010: 248). For Engster (2010), the disproportionate burden that widespread parental licensing would have on women is too great.

These objections to a system of universal parental licensing are certainly compelling. Yet notice that the first two apply equally well to our current system of parental licensing. If we have no good way of predicting who will abuse or neglect children, then we should not be licensing any parents, assuming that our purpose in doing so is to ensure that people will not mistreat their children. Moreover, if we could achieve this aim through the greater monitoring of parents rather than the licensing of them, then there is a strong case to be made for doing that instead. Philosophers who have expressed these concerns about universal parental licensing generally fail to extend them to the licensing of adoptive and foster parents. For example, Frisch does not even mention this form of licensing, while Archard tries to justify it by pointing to the fact that "natural parents," as he calls them, have a claim to "rear their own children" that seems, he says, to be stronger (he does not argue that it is stronger) than any claim an adoptive parent has to raise a child (2004: 189). ${ }^{8}$

\footnotetext{
${ }^{8}$ Engster mentions licensing for adoption (but not foster care) and tries to justify it in part by citing Archard's statement below, though mainly by pointing to the "greater viability" of such licensing compared to licensing for biological reproduction. For criticism, see McLeod \& Botterell (2014). We argue that licensing in the context of assisted reproduction is no less viable than it is in the context of adoption.
} 
Archard also says that,

if adoptive or foster parents are assessed it is not simply or solely to gauge whether they are fit parents as such. It is to evaluate whether or not they are well suited and situated to cope with children who, because they are being adopted or fostered, may present particular and possibly serious difficulties - those, for instance, arising from the fact that they have been rejected or abused by their natural parents. Adopted and fostered children differ from others in that they may be much harder to rear (2004: 191).

Before evaluating this argument, we want to be clear that insofar as Archard is suggesting that all adopted or foster children are "rejected or abused by their natural parents," then he is mistaken (since, of course, some of these children are relinquished by their parents in a morally responsible way, while others are not rejected at all, but find themselves without parents due to an unexpected death). He is correct, however, that these children can present some difficulties, at least early on in their placement. ${ }^{9}$ Still, the statement we have reproduced above is question begging. For Archard assumes without argument that we can devise a test to determine whether someone may be a fit parent for children who "may present particular or possibly serious difficulties" even as he denies that we can devise a test to determine whether an individual is a fit parent "as such." He insists that there must be evidence of our ability to predict who will be a minimally decent parent before we can license so-called "natural parents," but seems not to apply the same standard to the licensing of adoptive or foster parents.

Moving on, there are philosophers who object to greater licensing but make no attempts to defend the status quo, namely Jurgen De Wispelaere and Daniel Weinstock (2012). Like others, they target (the early) LaFollette and object to licensing schemes like his for two reasons. First, such schemes will inevitably and systematically generate false positives, meaning that they will overestimate the number of individuals who ought not to be granted a right to parent (2012: 200-201). Second, authors such as LaFollette radically underestimate the costs to people who are denied licenses, costs that De Wispelaere and Weinstock explain largely in terms of a right to parent. Following Harry Brighouse and Adam Swift (2006), they contend that people have a right to parent that is grounded in an interest in experiencing the special sort of intimacy that is characteristic of parent-child relationships. This intimacy makes parenting a unique good, that is, non-substitutable. As De Wispelaere and Weinstock write, "[t]he next best thing to raising a child might be taking care of a cat, but surely no one would insist that cats, lovely companions though they are, are in any way reasonable substitutes for children" (2012: 199). In De Wispelaere and Weinstock's view, given that there is no plausible proxy for the parent-child relationship and people generally have a strong

\footnotetext{
${ }^{9}$ For discussion, see Blake et al (2015), pp. 75-6.
} 
interest in being a parent, denying someone the opportunity to do so on the basis of a licensing scheme that over-generates false positives is seriously problematic. Notice in their work on parental licensing a shift away from arguments that are purely childcentric towards arguments that are parent-centric.

Notice too that De Wispelaere and Weinstock would reject Archard's claim that "natural parents" have more of a claim to parent their "own" children than adoptive parents do to parent any child. This is because, in their view, the fundamental interest in parenting a child is as much an interest of prospective adoptive parents as it is of biological parents. Since the goods of parenting (as described in Brighouse and Swift) do not depend on the existence of a biological connection to a child, De Wispelaere and Weinstock conclude at the end of their paper that we should reevaluate licensing for adoption and foster care as well, rather than simply reject licensing for biological parents.

\section{(C) Arguments for a new status quo}

Finally, some philosophers have argued that the status quo is morally unjustified without making any claims about what system of parental licensing, if any, ought to replace it. This has been our approach in the series of papers we have published together about parental licensing (McLeod and Botterell, 2014; Botterell and McLeod $2015,2016)$. We have considered the best arguments we could think of in support of the status quo and argued that none of them is any good. For example, like Overall we contend that if the justification for licensing adoptive parents is that with adoptions, there is a transfer of responsibility, then that justification applies equally well to some forms of assisted reproduction. On the other hand, if the justification for the status quo is that universal parental licensing is not feasible since many pregnancies are unplanned, then we need only point to the fact that there are no unplanned pregnancies among individuals who seek to form families via assisted reproduction. Perhaps the most interesting argument in support of the status quo, however, is the following: that what exempts biological parents from parental licensing is that such individuals exercise a right to reproduce when they have children, a right that adoptive parents fail to exercise. We have criticized this argument (Botterell and McLeod 2015) on two general grounds: first, that it is doubtful that there is a right to reproduce; and second, that to the extent that such a right exists, it is most plausibly understood as a right to parent, a right that adoptive parents have to the same degree as biological parents. In short, there is no morally salient difference, in our view, between parents who are currently licensed and those who are not that could morally justify the status quo on parental licensing.

In terms of what we think should replace the status quo, we lean towards greater frequency of licensing, although we do not support universal licensing for reasons having to do with the feasibility of licensing people who become parents through unassisted reproduction. Instead, we are inclined to endorse some licensing in 
the case of fostering and adoption (including family-member adoption), as well as in assisted reproduction, especially when it is government-funded. ${ }^{10}$ At the same time, we think greater attention needs to be paid to the effects of discrimination in the operation of parental licensing systems. In an effort to correct for this problem, we would recommend licensing that is minimal and employs objective measures, such as criminal background checks. We would also require extensive education of adoption practitioners and social workers about the role that implicit biases can play in assessments of people's capacity to be a good or decent parent. ${ }^{11}$ It is clear that discrimination exists in the current licensing of adoptive and foster parents: single people, LGBT people, and people with disabilities - to cite a few examples-can have a much harder time becoming licensed due to stereotypes about their ability to parent. Philosophers who argue in favour of parental licensing need to take this reality seriously, as we would aim to do in devising our own scheme of parental licensing.

\section{Conclusion}

We have framed our discussion of parental licensing using the backdrop of the status quo, rather than by asking the familiar question of whether there should be parental licensing at all. This choice was deliberate, and was motivated by two things. First, we wanted to emphasize that parental licensing exists; any discussion of parental licensing must acknowledge this fact and say something about whether, and if so how, the status quo can be justified. Second, and more importantly, we wanted to show, by situating philosophical arguments about parental licensing in relation to the status quo, that most of them reinforce biologism. They promote, in other words, a form of discrimination that targets adoptive and foster families, or more generally, non-biological families. We have also exposed in some of these arguments a lack of attention to other ways in which parental licensing can be discriminatory. These are flaws that seriously undermine the cogency of these arguments, in our view. That said, we acknowledge how difficult it is to devise a scheme of parental licensing that does not simply (and unnecessarily) reinforce inequalities in society. This task is challenging to be sure; nonetheless, it must be met before any form of parental licensing will be fully justified.

\footnotetext{
${ }^{10}$ Our thinking here is this: if the state is using taxpayer dollars or other means (such as tax credits) to defray the costs of assisted reproduction, then the state should make very sure that the individuals it is giving those financial benefits to are capable of being good parents to the children they-and the state-are helping to create. The best way to do this is through parental licensing.

${ }^{11}$ On implicit biases and how to take responsibility for them, see, for example, Kelly and Roedder (2008) and Holroyd (2012).
} 


\section{References}

Archard, D. (1990) "Child Abuse: parental rights and the interests of the child," Journal of Applied Philosophy 7(2): 183-194.

---. (2004) Children: Rights and Childhood. 2nd ed. New York: Routledge.

Baylis, F. and C. McLeod, eds. Family-Making: Contemporary Ethical Challenges (Oxford: Oxford University Press, 2014).

Blake, L., M. Richards, and S. Golombok. (2015) "The Families of Assisted Reproduction and Adoption." In F. Baylis and C. McLeod, eds: pp. 64-85.

Botterell, A. and C. McLeod. (2015) "Can a Right to Reproduce Justify the Status Quo on Parental Licensing?" In R. Vernon, S. Hannan, and S. Brennan, eds., Permissible Progeny. New York: Oxford University Press. pp. 184-207.

---. (2016) "Licensing Parents in International Contract Pregnancies," Journal of Applied Philosophy 33(2): 178-196.

Brand, A. E. and P. M. Brinich. (1999) "Behavior Problems and Mental Health Contacts in Adopted, Foster, and Nonadopted Children," Journal of Child Psychology and Psychiatry 40(8): 1221-1229.

Brighouse, H. and A. Swift. (2006) "Parents' Rights and the Value of the Family," Ethics 117: 80-108.

De Wispelaere, J. and D. Weinstock. (2012) “Licensing Parents to Protect our Children?" Ethics and Social Welfare 6(2): 195-205.

Engster, D. (2010) "The Place of Parenting within a Liberal Theory of Justice: The Private Parenting Model, Parental Licenses, or Public Parenting Support?" Social Theory and Practice 36(2): 233-262.

Frisch, L. (1981) “On Licentious Licensing: A Reply to Hugh LaFollette," Philosophy and Public Affairs 11(2): 173-180.

Haslanger, S. (2009) "Family, Ancestry, and Self: What is the Moral Significance of Biological Ties?" Adoption and Culture 2(1): 91-122.

Holroyd, J. (2012) "Responsibility for Implicit Bias," Journal of Social Philosophy 43(3): 274-306. 
Kelly, D. and Roedder, E. (2008) "Racial Cognition and the Ethics of Implicit Bias," Philosophy Compass, 3(3): 522-540.

LaFollette, H. (1980) “Licensing Parents," Philosophy and Public Affairs 9(2): 182-197.

---. (1981) “A Reply to Frisch,” Philosophy and Public Affairs 11(2): 181-183.

---. (2010) “Licensing Parents Revisited," Journal of Applied Philosophy 27(4): 327-343.

Mangel, C. P. (1988) “Licensing Parents: How Feasible?” Family Law Quarterly 22(1): 1739.

McLeod, C. and A. Botterell. (2014) "'Not for the Faint of Heart': Assessing the Status Quo on Adoption and Parental Licensing." In F. Baylis and C. McLeod, eds: pp. 151-167.

Overall, C. (2015) “Reproductive 'Surrogacy' and Parental Licensing," Bioethics 29(5): 353-361.

Sandmire, M. J. and M. S. Wald. (1990) "Licensing Parents-A Response to Claudia Mangel's Proposal," Family Law Quarterly 24(1): 53-76.

Taylor, R. S. (2009) "Children as Prospects and Persons: A Liberal Antinomy," Social Theory and Practice 35(4): 555-576.

Vopat, M. (2007) "Parent Licensing and Child Protection." In S. Brennan and R. Noggle, eds., Taking Responsibility for Children. Waterloo, ON: Laurier University Press. pp. 7396.

Westman, J. C. (1994) Licensing Parents: Can We Prevent Child Abuse and Neglect? Cambridge, MA: Perseus Publishing. 